\title{
SCALING ANALYSIS IN BEPU LICENSING OF LWR
}

\author{
FRANCESCO D'AURIA*, MARCO LANFREDINI, and NIKOLAUS MUELLNER \\ University of Pisa, Largo Lucio Lazzarino 1, 56100 Pisa, Italy \\ ${ }^{*}$ Corresponding author. E-mail : f.dauria@ing.unipi.it
}

Received July 13, 2012

\begin{abstract}
"Scaling" plays an important role for safety analyses in the licensing of water cooled nuclear power reactors. Accident analyses, a sub set of safety analyses, is mostly based on nuclear reactor system thermal hydraulics, and therefore based on an adequate experimental data base, and in recent licensing applications, on best estimate computer code calculations. In the field of nuclear reactor technology, only a small set of the needed experiments can be executed at a nuclear power plant; the major part of experiments, either because of economics or because of safety concerns, has to be executed at reduced scale facilities.

How to address the scaling issue has been the subject of numerous investigations in the past few decades (a lot of work has been performed in the 80thies and 90thies of the last century), and is still the focus of many scientific studies. The present paper proposes a "roadmap" to scaling. Key elements are the "scaling-pyramid", related "scaling bridges" and a logical path across scaling achievements (which constitute the "scaling puzzle"). The objective is addressing the scaling issue when demonstrating the applicability of the system codes, the "key-to-scaling", in the licensing process of a nuclear power plant. The proposed "road map to scaling" aims at solving the "scaling puzzle", by introducing a unified approach to the problem.
\end{abstract}

KEYWORDS : Licensing, Scaling, System Thermal Hydraulics, Best Estimate Plus Uncertainty, Safety Analysis

\section{INTRODUCTION}

Although the issue of designing small scale experimental facilities of prototypes in the field of thermal hydraulics is old and not restricted to nuclear reactor technology (see [1]), a considerable effort was needed to develop a structured methodology of designing small scale experimental facilities of nuclear power plants (NPP). A recent article provides a detailed summary on key concepts [2]. The present paper focuses on application of scaling in the field of licensing. Typically a national safety authority requires proof that a NPP can be operated safely and without posing a risk to the public. This proof is based on two main elements: experiments, and computer code safety analysis results. Due to economic reasons and safety concerns, most of the experiments that are needed cannot be performed in full scale; this means any applicant for a license not only has to deliver extensive safety analyses, but also has to answer the question "How can the scaling capabilities of currently available system codes be evaluated?". US NRC soon recognized the importance of the question and developed as guidance for applicants the CSAU methodology, where CSAU stands for Code Scaling Applicability and Uncertainty. A special issue of Nuclear Engineering and Design devoted to CSAU published in 1990 [3] provides a collection of articles by various authors summarizing the methodology and providing one example of its application. In the same volume [4] is dedicated only to the scaling issue in CSAU. Many important contributions to the scaling issue have been put forward, see e.g. 5-9]; the journal Nuclear Engineering and Design provided a special issue on the topic [10].

As mentioned, the recently published article [2] provided a summary on key achievements in the field of scaling and proposed a "roadmap-to-scaling", which potentially could provide solutions to the close the "scaling issue". The present paper shortly summarizes the roadmap, and expands on a selection of its key elements, while placing a stronger focus on licensing, and on the use of best estimate plus uncertainty (BEPU) computer codes in licensing.

Section 2 of the present paper provides the basis for the roadmap by establishing the roadmap nomenclature. Section 3 gives a short overview on the pursued procedure, and section 4 presents the actual roadmap followed by concluding remarks.

\section{NOMENCLATURE FOR SCALING ROADMAP}

Before introducing the roadmap, scaling terms that play a key role for the subject should be introduced and explained. As can be seen in Fig. 1, phenomena in nuclear reactor technology occurs in multiple scales, and involves multiple disciplines. The scope for scaling derives from the fact that the qualification (i.e. verification and validation, $\mathrm{V} \& \mathrm{~V}$ ) of thermal hydraulic system codes relies heavily 
THE SCOPE FOR SCALING

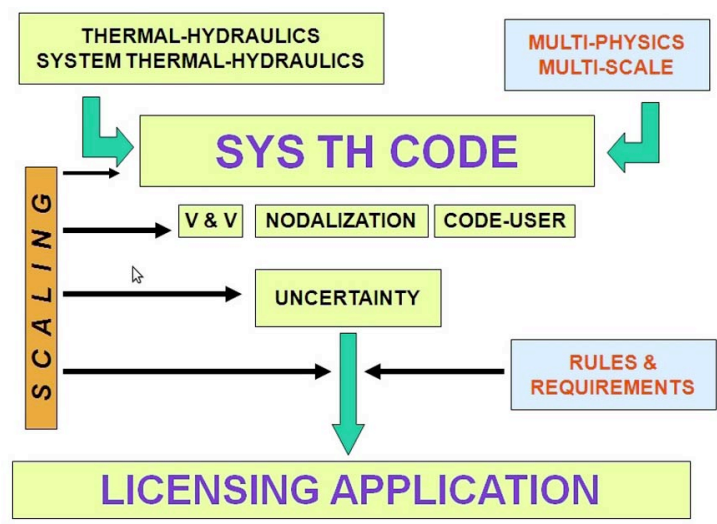

Fig. 1. The Scope for Scaling.

on experiments from facilities with the scale less than 1:1. This means that the scaling issue has to be addressed, the user has to be aware of the code capabilities and applicability domain, and the uncertainty stemming from the need to scale-up has to be evaluated, before the combination of system code, NPP model (nodalization) and code user is ready to perform safety analysis for licensing.

\subsection{Scaling Issue}

The origin of the scaling issues arises from the impossibility, or the huge cost, of performing meaningful experiments at full scale. For that reason, the capability of the numerical tools designed to simulate the behavior of a nuclear reactor can be tested only at a reduced scale. However, if an applicant for a license for a NPP chooses the BEPU framework to make their safety case (i.e. to use BEPU computational tools to support the licensing of the NPP), the solution of the scaling issue is mandatory.

\subsection{Scaling Controversy}

With the term "scaling controversy" one usually refers to the fact that engineers tend to have little faith in the results of experiments from a scaled down apparatus when it comes to critical applications (e.g. the first atomic bomb in Alamogordo 1945 has been tested in full scale). The scaling controversy is present as it relates to the peaceful use of nuclear power in the field of nuclear reactor system thermal hydraulics. Thermal hydraulic system codes are based on closure equations which, to be qualified, must be derived from experiments under steady state conditions and with fully developed flow. However it is unavoidable they are going to be used also under transient conditions. Fig. 2 shows one part of the scaling controversy. Since scaling inherently introduces distortions, experimental results cannot be directly scaled-up, and computer codes are needed. Fig. 3 shows a currently adopted, state of the
THE SCALING CONTROVERSY

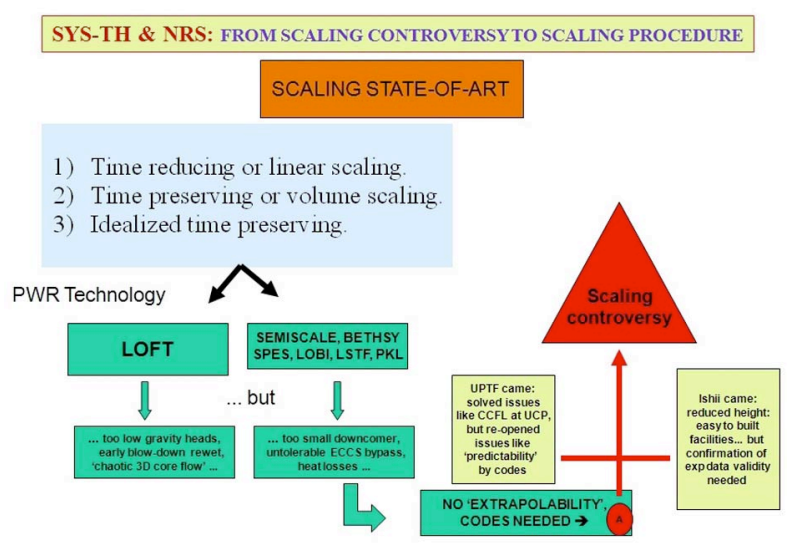

Fig. 2. The Scaling Controversy (Part 1 of 2).

\section{THE SCALING CONTROVERSY}

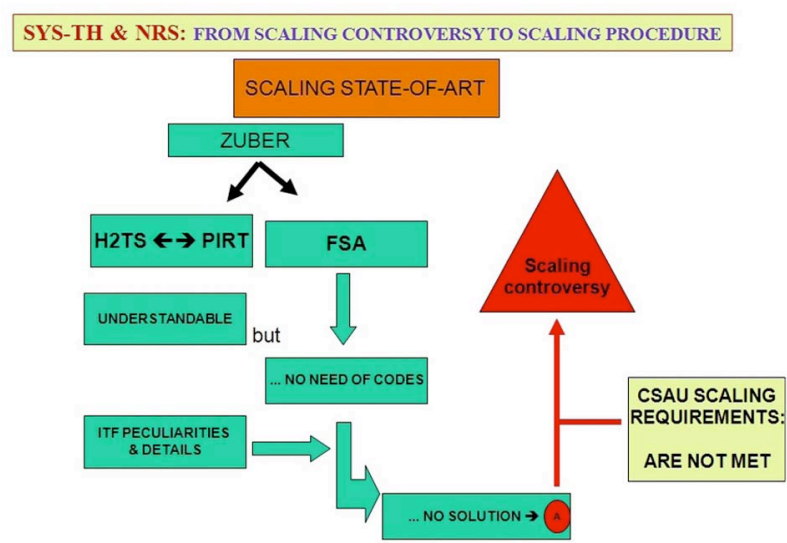

Fig. 3. The Scaling Controversy (Part 2 of 2).

art scaling procedures. H2TS refers to a scaling method introduced e.g. in [7], while FSA has been proposed in a series of papers [11-13]. The FSA procedure appears as an attempt to get rid of complex computational tools and to create a different framework for the analysis of complex scenarios, even though, according to [12] "... FSA is a scaling analysis, not a prediction tool. However, the combination of FSA and scaled experiments can sharply reduce the need for computer code calculations." This is in contradiction with the CSAU methodology (described section 2.11). The discrepancy between the conclusions that can be drawn from Fig. 2 and Fig. 3 is another aspect of the scaling controversy.

\subsection{Scaling Approaches}

To execute an experimental campaign, the designer has to choose a scaling technique. He has to establish a 
Table 1. Scaling Factors

\begin{tabular}{|c|c|c|c|}
\hline No & Scale factor & Meaning & Ref. \\
\hline 1 & $(\mathrm{G} \Delta \mathrm{p} / \mathrm{W})\left(\mathrm{c}_{\mathrm{v}} \mathrm{k} / \beta\right)$ & Mechanical compliance & Wulff (1996) \\
\hline 2 & $\Delta \mathrm{uG} / \mathrm{W}$ & Thermal compliance & \\
\hline 3 & $\mathrm{~W}_{\mathrm{HL}} \max / \mathrm{W}$ & Effect of heat losses & \\
\hline 4 & $\Delta \mathrm{p}_{\mathrm{PP}} \mathrm{G} / \mathrm{W}$ & Effect of pumping power & \\
\hline 5 & $\Delta \mathrm{h}_{0} \mathrm{G}_{\mathrm{ECC}} / \mathrm{W}$ & Thermal effect of ECC injection & \\
\hline 6 & $\left(\rho_{\mathrm{f}} / \rho_{\mathrm{g}}\right) \mathrm{G}_{\mathrm{CR}} / \mathrm{G}$ & Effect of break flow & \\
\hline 7 & $\mathrm{G}^{2}(\mathrm{~L} / \mathrm{A}) / \mathrm{gL}_{2 \mathrm{~F}} \mathrm{VDr}_{0}$ & Flow inertia in two phase flow & \\
\hline 8 & $\mathrm{G}^{2}\left(\mathrm{~N}_{\mathrm{Zu}}-\mathrm{N}_{\text {subc }}\right) / \mathrm{Dp}_{\mathrm{ppr}} \mathrm{fA}_{\mathrm{ht}}^{2}$ & Momentum flux changes in two phase flow & \\
\hline 9 & $\mathrm{~g}_{1,1,0} \mathrm{~W} \Delta \mathrm{t}_{\mathrm{phw}} / \mathrm{P}$ & Ratio of pressure change due to int. energy change to ref. pressure & Banerjee et al (1998) \\
\hline 10 & $\mathrm{G}_{\mathrm{ADS}} \Delta \mathrm{t}_{\mathrm{phw}} / \mathrm{M}$ & Ratio of integrated flow rate to reference mass & \\
\hline 11 & $\left(\Delta \mathrm{t}_{\mathrm{phw}} / \mathrm{V}\right)(\mathrm{gL} \Delta \mathrm{p})^{1 / 2}$ & Ratio of core make-up flow to vessel volume & \\
\hline 12 & $(\mathrm{fL} / \mathrm{D}+\mathrm{k})_{\mathrm{R}}$ & Friction and local pressure drop & Ishii et al. (1998) \\
\hline 13 & {$\left[(\mathrm{~L} / \mathrm{v})\left(\mathrm{d}^{2} / \mathrm{a}_{\mathrm{s}}\right)\right]_{\mathrm{R}}$} & Transport time/conduction time & \\
\hline 14 & {$\left[\mathrm{~A}_{\mathrm{ch}}=\mathrm{Av}\right)_{\mathrm{R}}$} & Break flow area scaling & \\
\hline 15 & $(\beta g W L)\left(r_{f} c_{p} v_{f}^{3} A\right)$ & 1-phase nat.circ. (operational mode) & Reyes and Hocreiter (1998) \\
\hline 16 & $\mathrm{H}_{\mathrm{fg}}(1-\mathrm{a}) \mathrm{aDrv} \mathrm{f}_{\mathrm{f}} \mathrm{A} / \mathrm{W}$ & 2-phase natcirc.and sump circ. & \\
\hline 17 & $\mathrm{~W}_{\mathrm{DC}} /(\mathrm{Gh})_{\mathrm{DVI}}$ & Down comer fluid heat-up & \\
\hline 18 & $\left(\mathrm{G}_{\mathrm{ADS}}+\mathrm{G}\right) / \mathrm{G}_{\text {irwst }}$ & IRWST injection & Yun et al. (2004) \\
\hline 19 & $\Delta \mathrm{t}_{\mathrm{phw}} \mathrm{j}_{\mathrm{kx}} / \mathrm{aL}$ & Momentum conservation along $\mathrm{X}$ & \\
\hline 20 & $\Delta \mathrm{t}_{\mathrm{phw}} \mathrm{j}_{\mathrm{kx}} / \mathrm{aL}$ & Momentum conservation along $\mathrm{Y}$ & \\
\hline 21 & $1 / \mathrm{S}_{\mathrm{x}}$ & Slip ratio along $\mathrm{x}$ & \\
\hline
\end{tabular}

rationale to scale down relevant thermal hydraulic phenomena from the full scale NPP to the scale of the facility. Since it is impossible to achieve perfect similarity between facility and full scale plant, the designer has to set priorities. Three different approaches are mentioned in the present section (for a complete description, please refer to [14]).

Time reducing or linear scaling: linear dimensions of the prototype are reduced using a fixed scale factor. This implies that the time between events during transients is reduced by the same factor.

With time preserving or volume scaling, each component of the prototype is reduced in size such that volume is reduced by a given factor, while maintaining elevations, and if possible, length. This results in a "one dimensional" facility, where typically time is preserved, but heat losses (due to the increased surface to volume ratio) play a larger role. For the loops, a choice has to be made whether the pressure drops or the length of the loops have to be conserved. Depending on the purpose of the facility, the de- signer chooses one or the other (e.g. in LOCA one typically would maintain pressure drops).

In idealized time preserving, idealized time preserving scaling is very close to volume scaling, with the difference that elevations do not necessarily have to be kept in scale, and that absolute priority is given to preserving the time scale.

\subsection{Scaling Factors}

Among other things, scaling factors can be used for designing a facility - after identification of NPP, transient and phase of the transient, expected and important phenomena in a given component the designer lists and ranks scaling factors (see Tab. 1 for a selection of commonly used scaling factors). Ideally for the selection of the "design factors" all selected scaling factors should be equal for prototype and facility (which is impossible). So usually a compromise has to be found. 


\subsection{Design Factors}

The dimensionless design factors are applicable for the design of facilities and experiments. While design factors can be derived directly from the principles of conservation of mass, momentum and energy, the scaling factors are derived from the more or less complex balance equations for single and two phase flow. Scaling factors obtained from simplified balance equations can be used to derive design factors. A synthesis list of design factors that characterize the power-to-volume scaling can be found in Tab. 1 [15-16],

\subsection{Objectives for Scaling Analysis}

The objectives of a scaling analysis (within the scope of a BEPU safety analyses for the licensing process for NPP) is to demonstrate the scaling capabilities of the adopted computational tools, including the code, the nodalization and the analyst (or the code user). Furthermore, the qualification of the computational tools constitutes a complementary issue.

\subsection{Scaling Puzzle}

Numerous activities can be classified and are actually classified in the literature as scaling related research. They form what has been termed the "scaling puzzle" [2]. To provide an example and a rough visualization of the idea, Fig. 4 shows the scaling activities performed at UNIPI (discussed in the section above) that contribute to the scaling puzzle. From Fig. 4 one can see that a road-map is needed to guide through those activities. The list below makes references to the sketches 1 to 11 in Fig. 4.

1. Origin for accuracy extrapolation.

2. "Dimensional" phase space results for various NC experiments from PWR-ITF.

3. The "in-principle" or the "UMAE-precursor" flow diagram (which was used to obtain NPP transient scenario either by ITF experiments or by ITF qualified calculations, but is no longer used in the framework of UMAE and of CIAU application).

4. Data accuracy as a function of Kv (logarithmic scale is adopted in the horizontal axis).

5. A scale independent formula for single phase natural circulation in PWR.

6. The flow diagram of UMAE: The scaling-up process should be considered a failure if the established acceptability conditions are not met.

7. Results from the application of the FFTBM for quantifying the accuracy in the case of Counterpart Test: calculated values of the errors do not depend upon scaling. It may be noted that an analytical formulation of the accuracy different from FFTBM is used for extrapolation.

8. Demonstration that thermal-hydraulic phenomena (NC in the present case) depend upon scaling.
9. Use of the natural circulation flow map to evaluate the (natural circulation) performance of a NPP.

10.Incorrect (not recommended) use of a code input deck (or nodalization) for scaling analysis.

11.The simplified flow diagram of CIAU emphasizing the "error-filling" and the "error-extraction" processes.

\subsection{Scaling Pyramid}

The following section and Fig. 5 describe the "scaling pyramid", which is an important contributor to the scaling roadmap. As also stated in [2], the water cooled nuclear reactor system, in relation to scaling, can be assumed at the top of a virtual multi-D pyramid whose bases are constituted by the research achievements and by the technology findings in the area of system thermal-hydraulics. Several edges, i.e. the scaling bridges, connect, more or less tightly, to the research achievements and the technology findings at the top of the pyramid. The NPP and the related phenomena do not constitute an unbeaten fortress on the top of a hill, but instead vice-versa. Scaling research results have contributed to make the phenomena and the scenarios at the top of the pyramid clear. The NPP is the central-toptriangle of the pyramid, code-nodalization qualification and uncertainty evaluation constitute the pyramid bottom boundary. Important comments related to the bottom of the pyramid are that the code alone, including all of its implemented models and the numerical solution methods, is not the only significant part of the analysis. The nodalization and the code-user also significantly influence the quality of an NPP transient analysis. Furthermore, code, nodalization and code-user need qualification independent of scaling. Lack of qualification of any of those three elements contributes to the "scaling controversy".

Any best-estimate code calculation needs to be accompanied with the uncertainty of the results to be meaningful, and the scaling issue must be addressed together and consistently with uncertainty (which is also required when adopting the CSAU methodogy [2]). The relationship between scaling, qualification of computational tools constitutes a relevant matter for the licensing processes of NPP.

\subsection{Scaling Bridges}

This section again follows very closely [2] and describes the scaling bridges that are depicted in Fig. 5, which reports a non-exhaustive set of scaling bridges connecting the NPP with what we may call the established-understanding. All points of the list below refer to Fig. 5 .

- NPP operational transients, left top box. For a reduced range of parameter values, codes-nodalizations results are compared with transients data measured in NPP e.g. [17]. No code deficiency is drawn from the papers dealing with the simulation of operational transients. However, small regions of the phase-space domain at 


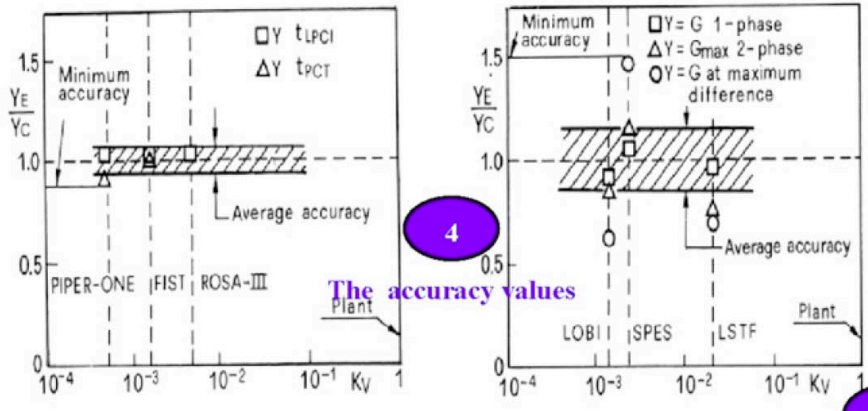

Bovalini et al., 1993.

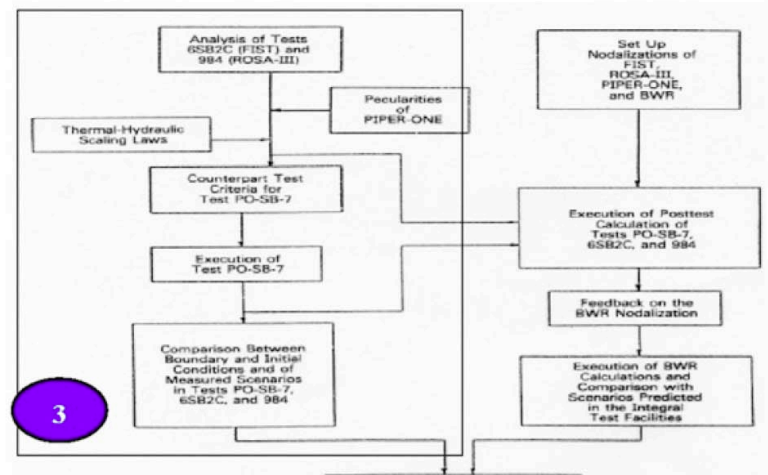

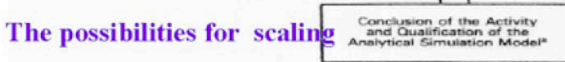

Bovalini et al., 1992.

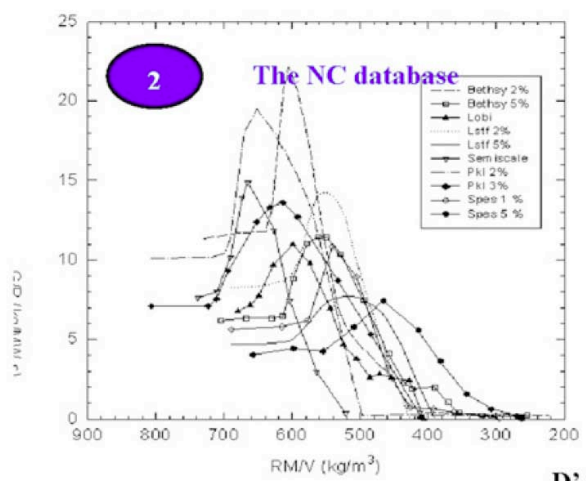

D'Auria \& Frogheri, 2002, and D'Auria et al., 2008.

D'Auria et al., 1991.

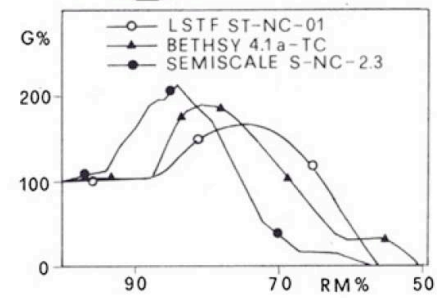

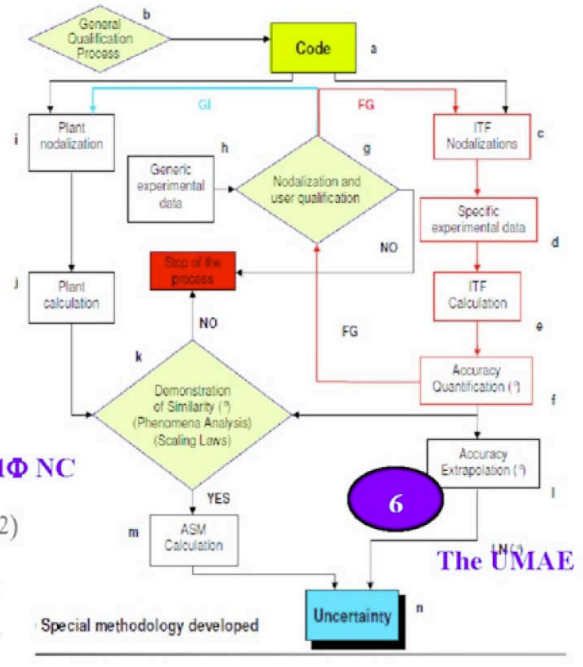

D'Auria et al., 1995.

\begin{tabular}{|c|c|c|c|c|c|c|c|c|c|c|c|c|}
\hline & \multicolumn{2}{|c|}{ BL.34 } & \multicolumn{2}{|c|}{ BL-44 } & \multicolumn{2}{|c|}{ SB-03 } & \multicolumn{2}{|c|}{ SB-04 } & \multicolumn{2}{|c|}{$6.2 \mathrm{TC}$} & \multicolumn{2}{|c|}{$C .21$} \\
\hline & $\mathrm{M}$ & WE & $\mathrm{M}$ & $\overline{W F}$ & AA & $W F$ & AA & WF & & WF & $\mathrm{M}$ & WE \\
\hline PRZ pressare & 0.096 & 0.052 & 0.124 & 0.053 & 0.082 & 0.077 & 0.097 & 0.061 & 0.102 & 0.072 & 0.090 & 0.051 \\
\hline SG gressure & 0.384 & 0.045 & 0.164 & 0.045 & 0.094 & 0.064 & 0.072 & 0.078 & 0.051 & 0.042 & 0.070 & 0.05 \\
\hline Accoun. preessure & 0.115 & 0.127 & 0.079 & 0.043 & 0.233 & 0.134 & 0.101 & 0.054 & 0.065 & 0.039 & 0.104 & 0.045 \\
\hline Core inke flesid temperanure & 0.026 & 0.030 & 0.026 & 0.015 & 0.045 & 0.052 & 0.047 & 0.030 & 0.039 & 0.0560 & 0.437 & 0.042 \\
\hline Core outle fluid temperature & 0.032 & 0.044 & 0.043. & & & & 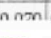 & in & 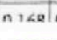 & in nos & & \\
\hline Upper heed duid temperature & 0.240 & 0.034 & 0.250 & 0.0 & 7 & & The & use & of $\mathrm{FI}$ & FTB & M & $=$ \\
\hline Intagral bretk flownine & 0.103 & 0.046 & 0.125 & 0.05 & & & vousent & 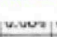 & 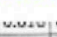 & 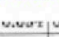 & werot & 0.087 \\
\hline SG DC bot Aluid temporatare & 0.164 & 0.096 & 0.516 & 0.057 & 0.051 & 0.084 & 0.095 & 0.092 & 0.135 & 0,056 & 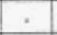 & \\
\hline Brealk flowrate & 0.49 & 0.120 & 0.617 & 0.110 & 0.940 & 0.117 & 0.920 & 0.170 & 0.445 & 0.1250 & 0.657 & 0.088 \\
\hline ECCS int flowrate & 0.456 & 0.061 & 0.560 & 0.059 & 0.106 & 0.042 & 0.695 & 0.052 & 0.042 & 0.021 & 0.349 & 0.049 \\
\hline
\end{tabular}

D'Auria \& Ingegneri, 1998.

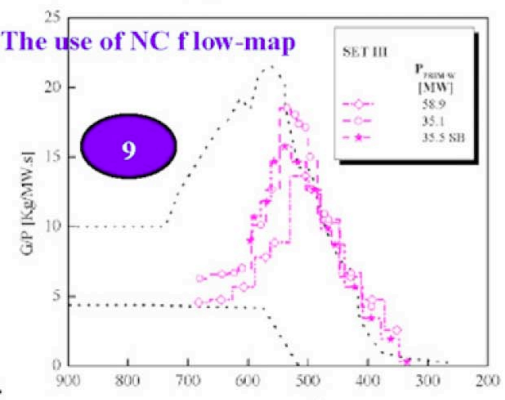

RMN [K,g m']

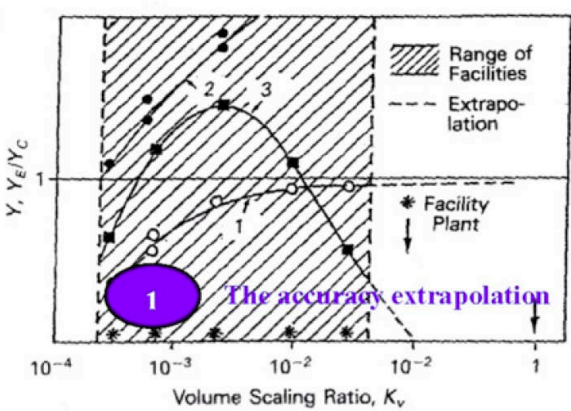

D'Auria et al., 1988.

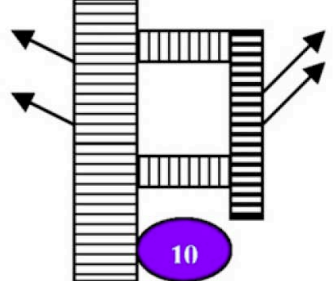

Scaling by enlarging a nodalization

D'Auria \& Vigni, 1985.

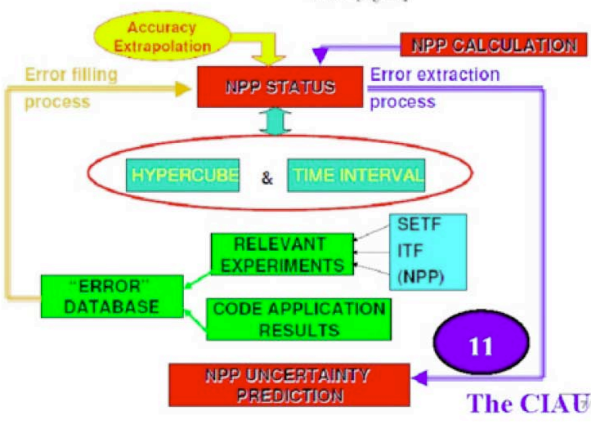

D'Auria \& Giannotti, 2000.

Fig. 4. The Scaling Puzzle. 


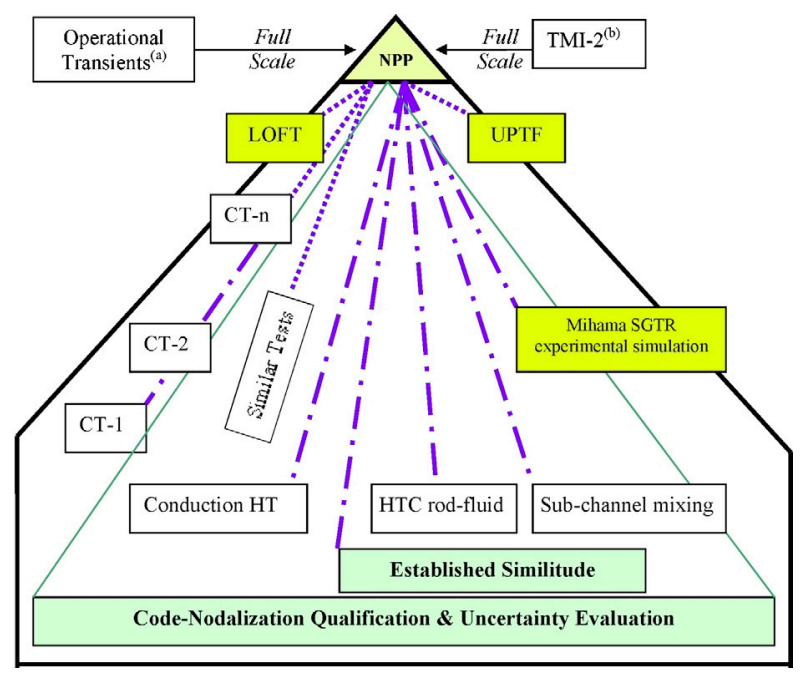

Fig. 5. The Scaling Pyramid.

full scale are within assessed code capabilities.

- TMI-2, right top box. In the case of the TMI-2 accident, thermal-hydraulic phenomena occurred before core melt and involving phase non equilibrium, could be predicted at full scale during a couple of hours of transient evolution without showing any model deficiency.

- LOFT and UPTF, right and left middle boxes. The existence of those two facilities (including CCTF and SCTF) and the completion of the related research programs need proper consideration when dealing with the scaling issue: phenomena and parameters have been measured at full scale and must be considered. Those two boxes are connected with the NPP through the line "straightforward scaling connection"

- NPP Mihama-2 SGTR (Steam Generator Tube Rupture), right middle box. The capability was demonstrated to reproduce by an experiment of the NPP performance. In this case, no computational tool was needed to show the capabilities of the concerned scaling procedure and the adopted test design factors [18].

- The Counterpart Tests, left lined boxes. The related main roles within the Scaling Pyramid are: (1) possibility to confirm the understanding of scaling factors by using experimental data; (2) opportunity to demonstrate that accuracy of code prediction does not depend upon scale (namely volume scale).

- The Similarity Tests, left-middle lined box. The same statement and the conclusions given for the Counterpart Tests can be applied to the Similar Tests. It can be recalled that Similar Tests, as related to Counterpart Tests, require a lower amount of work for test designand facility hardware preparation and a larger amount of work for interpretation of measured scenarios.

- Conduction Heat Transfer, middle-bottom left box.
The prediction of any NPP transient scenario needs a variety of models, e.g. embedded into a computer code as outlined in Section 2.4. Some of those models may not be at the origin of scaling issues which need investigation. One example is the conduction heat transfer that is modeled by the Fourier balance equations and by the Fourier law e.g.[19]. Thus whatever is connected with the conduction heat transfer in the NPP constitutes an "island of knowledge" and "no further scaling (theory)" is needed.

- HTC rod-fluid, middle-bottom central box. The parameter "HTC rod-fluid" together with the conduction heat transfer in the fuelrod (not affected by scaling) constitutes the key for determining the CHF (Critical Heat Flux) occurrence and the rod surface temperature. This, at least in case of LOCA, constitutes the most relevant safety parameter and justifies the presence in the diagram. The core of a nuclear power, typically 4 $\mathrm{m}$ diameter, $4 \mathrm{~m}$ height, can be seen as an ensemble of replicating elements that are the fuel rods, the spacer grids or the fuel bundles that interact with the fluidcoolant under different thermal-hydraulic conditions (basically characterized by pressure, velocities, voidfraction, temperatures). The replicating elements are characterized by "small scale geometric dimensions". Several tens of experimental programs to measure the various relevant parameters, including the HTC rodfluid, have been completed and related findings are available in the literature (e.g.[20]). There is no reason to expect a thermal-hydraulic performance of the replicating elements, when these are installed in the NPP. This is different from what is measured in the experiments, i.e. not only the single rod, but ensembles of rods, or even a number of fuel bundles. The same considerations apply to all thermal-hydraulic parameters 
Table 2. Design Factors

\begin{tabular}{|c|c|c|c|}
\hline No & Design factor & Scaling of & Zone of the ITF \\
\hline 1 & $\mathrm{~K}_{\mathrm{v}}=\mathrm{k}_{\mathrm{v}-\max }$ & Volume & Each zone \\
\hline 2 & $\mathrm{~K}_{\mathrm{h}}=1$ & Elevation change & $\begin{array}{l}\text { CO,CO-BY,UP,HL-v,PRZ,SU-LI, LS, MCP, DC, } \\
\text { SGI,SGO,SG UT PS,SG UT SS, SG DC }\end{array}$ \\
\hline 3 & $\mathrm{~K}_{\mathrm{NL}}=1$ & Number of loop & System \\
\hline 4 & $\mathrm{~K}_{\mathrm{h}}<=1$ & Elevation change & LP,UH,SG UP-SEP, SG UH DRY, HL-h, CL-h \\
\hline 5 & $\mathrm{~K}_{\mathrm{L}}=1$ & Length of horizontal components & \\
\hline 6 & $\mathrm{~K}_{\mathrm{A}}=\mathrm{K}_{\mathrm{abr}}=\mathrm{k}_{\mathrm{v}}$ & Cross and break area & Each vertical zone \\
\hline 7 & $\mathrm{~K}_{\mathrm{d} . \mathrm{eq}}=1$ & Hydraulic diameter & $\mathrm{CO}, \mathrm{SG} \mathrm{UT}$, each zone if possible \\
\hline 8 & $\mathrm{~K}_{\mathrm{W}}=\mathrm{K}_{\mathrm{v}}$ & Power & $\mathrm{CO}, \mathrm{SG} \mathrm{UT}$ \\
\hline 9 & $\mathrm{~K}_{\mathrm{t}}=1$ & Time & System \\
\hline \multirow{2}{*}{10} & $\mathrm{~K}_{\mathrm{q}}=1$ & Linear power & $\mathrm{CO}, \mathrm{SG} \mathrm{UT}$ \\
\hline & $\mathrm{K}_{\mathrm{q},},=1$ & Volumetric power & \\
\hline 11 & $\mathrm{~K}_{\text {f.r.g.m }}=1$ & Fuel rod geometry and material & $\mathrm{CO}$ \\
\hline 12 & $\mathrm{~K}_{\mathrm{T}}=1$ & Fluid temperature & Each zone \\
\hline 13 & $\mathrm{~K}_{\mathrm{p}}=1$ & Pressure & \\
\hline 14 & $\mathrm{~K}_{\mathrm{r} . \mathrm{s} . \mathrm{T}}=1$ & Rod surface temperature & $\mathrm{CO}, \mathrm{SG} \mathrm{UT}$ \\
\hline 15 & $\mathrm{~K}_{\text {r.s.h.f. }}=1$ & Rod heat flux & \\
\hline 16 & $\mathrm{~K}_{\text {p.h.t.a }}=\mathrm{K}_{\mathrm{v}}$ & Passive heat transfert area & Each zone \\
\hline 17 & $\mathrm{~K}_{\text {th.p.s. }}=1$ & Thickness of passive structure & \\
\hline 18 & $\mathrm{~K}_{\text {h.l.e. }}=1$ & Enviromental heat losses & \\
\hline 19 & $\mathrm{~K}_{\mathrm{G}}=\mathrm{K}_{\mathrm{v}}$ & Mass flow rate & \\
\hline 20 & $\mathrm{~K}_{\mathrm{Dp}}=1$ & Pressure drop & \\
\hline 21 & $\mathrm{~K}_{\text {G.ecc }}=\mathrm{K}_{\mathrm{v}}$ & ECC flow & \\
\hline 22 & $\mathrm{~K}_{\mathrm{T.ECC}}=1$ & ECC temperature & \\
\hline 23 & $\mathrm{~K}_{\mathrm{G} . S \mathrm{~L}}=\mathrm{K}_{\mathrm{v}}$ & Steam line flow rate & SG, UH-DRY \\
\hline 24 & $\mathrm{~K}_{\mathrm{G} . \mathrm{fw}}=\mathrm{K}_{\mathrm{v}}$ & Feed water flow & $\mathrm{SG}, \mathrm{DC}$ \\
\hline 25 & $\mathrm{~K}_{\mathrm{T} . \mathrm{fw}}=1$ & Feed water temperature & \\
\hline 26 & $\mathrm{~K}_{\mathrm{RR}}=1$ & Recirculation Ratio & \\
\hline 27 & $\mathrm{~K}_{\mathrm{MCP} \mathrm{ch}}=1$ & Non-dimensional charatteristic for pumps & $\mathrm{MCP}$ \\
\hline 28 & $\mathrm{~K}_{\mathrm{VLV} \text { ch }}=1$ & Non-dimensional charatteristic for valve & All valves \\
\hline
\end{tabular}

which characterize the interaction between fuel bundles and coolant, including pressure drops in single and two phase flows. Thus, "no further scaling (theory) need" is identified for those situations.

- Sub-channel mixing, middle-bottom right box. Whatever is written in relation to HTC rod-fluid is relevant in this case. Relevant scientific and technological information can be found in [21], although a large progress in recent years is due to the CFD (Computational Fluid Dynamics) and similar tools [22]. Furthermore, computational capabilities in this case are more adequate in the case of single phase flows 
Table 3. Excerpt of Summary Table in [22]

\begin{tabular}{|c|c|c|c|c|c|}
\hline Dimensionless group & Physical meaning & AP600 & ROSA & SPES & OSU \\
\hline$\left(\mathrm{t}_{0} / \mathrm{v}_{0}\right)\left(\mathrm{g}_{0} \mathrm{~L}_{\mathrm{o}} / \mathrm{R}_{0}^{\prime}\right)^{1 / 2}$ & Ratio of CMT flow to vessel volume & 0.82 & 0.28 & 0.77 & 1.21 \\
\hline $\mathrm{G}_{0} \mathrm{~A}_{0} \mathrm{t} 0 / \mathrm{V}_{0} \mathrm{r}_{0}$ & Ratio of ADS flow to vessel volume & 0.96 & 1.26 & 2.00 & 0.98 \\
\hline $\mathrm{G}_{0} \mathrm{~A}_{0} / \mathrm{r}_{0}\left(\mathrm{R}_{0}{ }_{0} / \mathrm{g}_{0} \mathrm{~L}_{0}\right)^{1 / 2}$ & Ratio of ADS flow to CMT flow & 1.18 & 1.54 & 2.58 & 0.81 \\
\hline
\end{tabular}

compared with two-phase flows.

- Established similitude, bottom central-right box. Established dimensionless groups (or numbers) in fluid mechanics and heat transfer are widely used by the scientific community (a couple of dozen of those numbers can be found in the Appendix G of the book by [19].) The observation here is that those numbers create specific islands of established knowledge (i.e. the same comment given in the case of conduction heat transfer) when predicting the transient performance of NPP. For instance, when making reference to single phase flow (for the sake of simplicity), nobody doubts that the Re-dependency of friction pressure drop that is measured and calculated in a $0.01 \mathrm{~m}$ diameter pipe is also valid in the case of a $1 \mathrm{~m}$ diameter pipe. This creates a further connection between established science and (full scale) NPP performance.

\subsection{Scaling Facts}

The present section summarizes a number of circumstances ("scaling facts") that will be important for deriving the "scaling roadmap" in Section 4.

1. [23] reports a scaling study focusing on the facilities ROSA, SPES, and OSU, which all simulate the AP-600. About 30 scaling parameters were found. Tab. 3 reports an excerpt of a summary table provided in [23]. Although reported scaling factors show significant differences between the facilities and the prototype, the authors conclude that "the same important processes occurred in the ITF as might be expected in the AP-600", since "the magnitude of the non-dimensional coefficients were similar for the ITFs and the AP-600. While one can agree on the conclusion, it is questionable if the reported basis for the conclusion is valid.

2. A few dozen ITF and several hundreds of SETF have been constructed, and about one order of magnitude more experiments have been performed. The resulting experimental database constitutes the result of a several billion dollar investment.

3. About one dozen thermal hydraulic system codes exist. The development time of those codes can be quantified to (order of magnitude) 100 million years, counting also the time needed to qualify the codes $(\mathrm{V} \& \mathrm{~V})$. The codes usually are accompanied by independent code qualification programs, comprising order of magnitude 1000 code users. The investment for development and qualification of these tools to the current state can be estimated to (order of magnitude) 100 million dollars.

4. Certain phenomena cannot be scaled up, and scaling effects are unavoidable. Examples for such phenomena are two phase critical flow, natural circulation, or counter current flow limiting.

5. Accuracy, defined as the difference between code prediction and experimental results, is a measure of the code capability in predicting experimental data. Accuracy is a statistical quantity that is independent of scaling.

6. Although expensive, few test facilities have been built in scale 1:1 (e.g. UPTF). Furthermore, experimental data from plants is available not typically on purpose but as a byproduct of an accident - e.g. Mihama event). This means few full scale "tests" are available.

7. Design factors (see section 2.5) are derived from basic principles like conservation of mass, energy and momentum, while most scaling factors are derived from complex balance equations.

8. Counterpart tests have been performed, thereby allowing the detailed study of the influence of scale in nuclear reactor technology.

\subsection{CSAU and Scaling}

Scaling plays a central role in the CSAU procedure. Nuclear Engineering and Design dedicated a full edition to the role of scaling [3]. While the procedure is very clear and concisely structured from a logical point of viewfew, some of the resulting requirements are difficult to meet, or leave the user without a clear indication on how to meet the requirement. E.g. [3] states that "Parameters ... such as HTC, pump performance ... must have their uncertainty from ... SET data ...the comparison must encompass data from a range of TF scales, to facilitate extrapolation ... Otherwise conservative estimate" and further "... since there are insufficient data to estimate ... the full range of uncertainty as obtained from the $1 / 3$ scale W pump ... was used to analyze PCT uncertainty". The sub-steps to address the scaling issue as indicated in [3] are

1 Specify test facilities

2. Provide facility documentation

3. Evaluate effect of distortions on important processes 


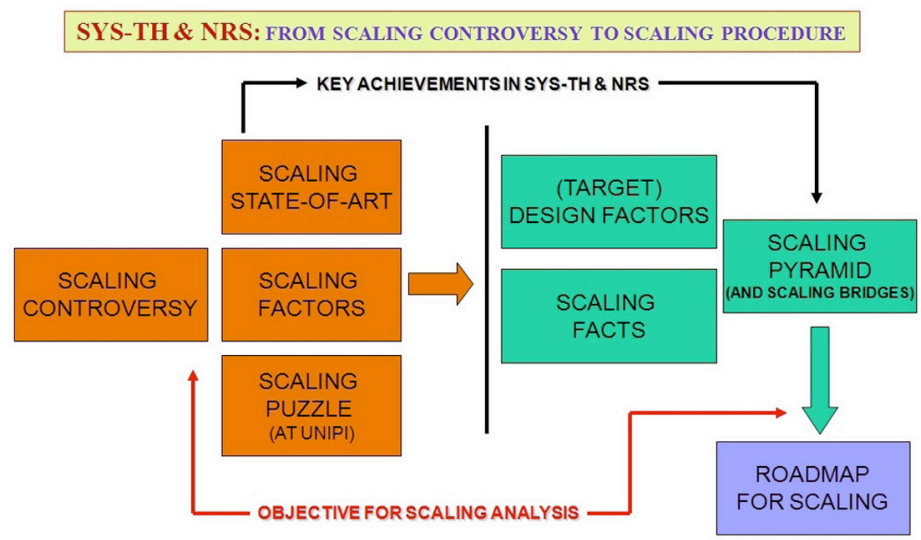

Fig.6. From the Scaling Controversy to the Scaling Roadmap.

4. Specify bias

5. Evaluate whether the database covers the NPP

6. Specify bias

7 Evaluate scale-up capability of closure relations

8. Specify bias

9. Evaluate whether closure relation cover the NPP range

10.Specify bias

It has to be noted that regarding items 5 and 9 one can almost with certainty give "no" as an answer to the question. Which leads to the need to specify the bias (items 4,6,8 and 10). However, the CSAU does not provide a procedure how to evaluate the bias.

\section{PURSUED PROCEDURE}

Section 2 gave all the elements that are needed to understand how to arrive at a scaling roadmap. The present section outlines the procedure, which is also explained in Fig. 6 . The need for a scaling roadmap is best constituted by the scaling controversy. Scaling factors, the scaling puzzle and current state of the art scaling techniques give rise to the need to single out main concepts (while perhaps also neglecting dead ends) and to structure the vast amount of generated research. The well established design factors together with the scaling facts constitute in part the way to the scaling road map, while the scaling pyramid aims at defining the scope and objective of the scaling issue. Finally, the next section proposes a road map to scaling that might close the scaling issue.

\section{ROADMAP FOR SCALING}

The "roadmap for scaling" is introduced and shown in Fig. 7. This roadmap has also been presented in [2], and the description hereafter is mainly following [2]. The present "roadmap to scaling" aims at finding a way through the "scaling puzzle" maze, adopting a thermal-hydraulic code system as the "key-to-scaling". The purpose for the proposed approach to scaling is to demonstrate that a transient scenario calculated by a system thermal-hydraulic code with reference to an assigned NPP (i.e. the model) is validated related to scaling. The proposed approach to scaling, or roadmap to scaling, aims at showing that all the ideas or scaling spot studies can be unified or integrated within the roadmap.

The detailed description of the objective itself implies the fulfillment of the step (I) of the roadmap (see below). This constitutes a requisite for the planning of the remaining steps. The objective is thus reformulated with more detail in the paragraph hereafter.

Within the licensing process of water cooled reactors where best estimate codes are used (BEPU approach) a typical request from Regulatory Authority deals with the demonstration of the scaling at different levels. This implies the demonstration of the scaling capabilities of the adopted computational tools including the code, the nodalization and the analyst or code user (the qualification of the input data constitutes a complementary issue not necessarily connected with scaling). Thus, objective of the roadmap is to streamline an answer to the regulatory request. Steps of the roadmap to scaling are as follows and includes the flow diagram given in Fig. 7.

The framework and the objective for the scaling analysis:

I) Establishing the objective and the scope for the scaling analysis including the significant boundary conditions (the objective and scope are defined in the paragraph above). This implies the identification of the reference NPP and the consideration of accident scenarios.

Phenomena investigation and obtaining scaling parameters:

II) Select the power-to-volume, full-height, fullpressure, time preserving approach as the reference scaling approach. This is true at the system level 


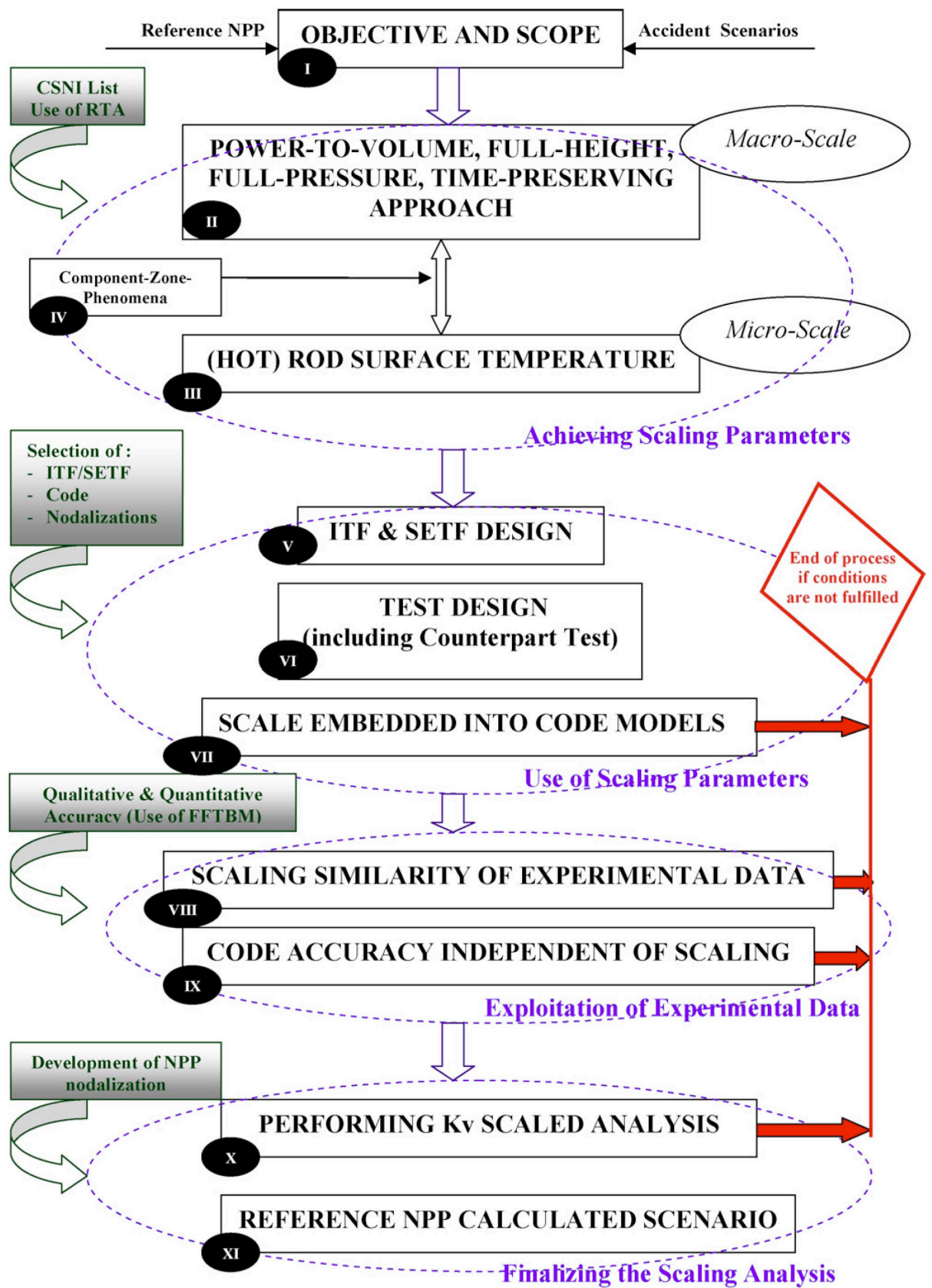

Fig. 7. The Roadmap to Scaling.

or at the macro-scale level.

III) Select the (hot) rod surface temperature as reference parameter at local level or at the micro-scale level, as the most important safety related parameter. This parameter may be different indifferent frameworks (e.g. in new reactor design or in case of selected SB-LOCA, main focus at micro-scale might be the core liquid level).

IV) Consider the component-zone-phenomena scaling.
Use of scaling parameters (e.g. based on the design criteria inTable 2)

V) Confirm the suitability of the scaling design of selected ITF.

VI) Confirm the suitability of the design of selected tests including counterpart tests.

VII)Confirm the suitability of the code design against scaling.

Exploitation of experimental data and demonstration that 
VIII)Experimental results are similar.

IX) Accuracy of code prediction is independent of scale.

Development of NPP nodalization and

$\mathrm{X})$ Performing $\mathrm{Kv}$-scaled analysis.

XI) Performing reference NPP accident analysis and evaluation of results

\section{CONCLUSIONS}

The present paper was looking at scaling in the scope of the licensing process where best estimate computational tools are adopted, expanding a recently published paper on the subject by D'Auria and Galassi [2]. It introduced the "scaling controversy". The parallel established between the dimensionless design factors, derived from basic principles of mass momentum and energy conservation and used for the design of facilities and experiments, and the scaling factors, derived from balance equations, might help the understanding of the "scaling controversy".

The tight connection between the scaling issue and the issues of code qualification, nodalization development and qualification, as well as of the user or the analyst training and expertise, was observed.

The power-to-volume scaling, aiming at the condition of time preserving when simulating complex accident scenarios in NuclearPower Plants, is the best suited approach for the objective and the context established for the present paper.

The "roadmap for scaling" constitutes the main achievement from the present work. Here, the computational tools are selected as the pivot elements for applying the procedure. The code is one element responsible for proper scaling (i.e.the "key-to-scaling"); however, nodalization and code-user are equally as important as the code in the scaling process. The quality of code can be estimated only once in the lifetime of the code, but the quality of the code-user and of the nodalization must be estimated before each(scaling) application of the procedure. Noticeably, arbitrary tuning must be avoided and any tuning introduced for the prediction of one transient must be shown as applicable to all transients that are at the basis of the scaling procedure, including those transients considered within the code qualification process.

The application of the "roadmap for scaling" is strictly connected with the availability of experimental data. The experimental database gathered so far within the system thermal-hydraulics area, including Counterpart Tests and Similar Tests, make possible the full application of the roadmap.

\section{REFERENCES}

[ 1 ] E. Buckingham, “On physically similar systems; illustrations of the use of dimensional equations." Phys. Rev. 4, pp.345 -376 (1914).
[2] F. D'Auria and G. M. Galassi, "Scaling in Nuclear Reactor System Thermal Hydraulics", Nuclear Engineering and Design, 240, pp. 3266-3293 (2010)

[3] Special Issuedevoted to CSAU, Nuclear Engineering and Design, 119-1, (1990)

[4 ] N. Zuber, G. E. Wilson, B. E. Boyack, I. Catton, R. B. Duffey, P. Griffith, K. R. Katsma, G. S. Lellouche, S. Levy, U. S. Rohatgi, W. Wulff, "Evolution of Scale-up Capabilities of Best Estimate Codes", Nuclear Engineering and Design, 119, pp. 97-109 (1990)

[ 5 ] F.D'Auria, G. M. Galassi and L. Moschett "Assessment of scaling criteria adopted in designing nuclear power plants experimental simulators". Nuclear Materials, p.130 (1985)

[6] M. Ishii, S.T. Revankar, T. Leonardi, A. Dowlati, M.L. Bertodano, I. Babelli, W. Wang, H. Pokharna, V.H. Ransom, R. Viskanta and J.T. Han"The three-level scalingapproach with application to the Purdue University Multi-Dimensional IntegralTest Assembly (PUMA)", Nuclear Engineering and Design 186, pp.177-211 (1989)

[ 7 ] N.Zuber, G.E. Wilson, M. Ishii, W. Wulff, B.E. Boyack, A.E. Dukler, P. Griffith, J.M.Healzer, R.E. Henry, J.R. Lehner, S. Levy, F.J. Moody, M. Pilch, B.R. Sehgal, B.W. Spencer, T.G. Theofanous and J. Valente, "An integrated structure and scaling methodology for severe accident technical issue resolution: development of methodology", Nuclear Engineering and Design 186, pp. 1-21. (1998)

[ 8 ] N. Zuber, "The effects of complexity, of simplicity and of scaling in thermalhydraulics", Nuclear Engineering and Design, 204, pp. 1-27 (2001).

[9] D'Auria, F., Debrecin, N., Galassi, G.M.,. "Outline of the uncertainty methodology based on accuracy extrapolation (UMAE)". Nuclear Technology, 109 (1), pp. 21-38. (1995)

[10] Special Issue devoted to Scaling, Nuclear Engineering and Design 186, (1998)

[11] N. Zuber, W.Wulff, U.S. Rohatgi and I. Catton, “Application of fractional scalinganalysis (FSA) to loss of coolant accidents (LOCA) - Part 1: Methodology development" In: Proceedings of the International Top. Meet. On Nuclear Reactor ThermalHydraulics (NURETH-11), Avignon, France (2005)

[12] W. Wulff, N. Zuber, U.S. Rohatgi, I. Catton, “Application of Fractional ScalingAnalysis (FSA) to Loss of Coolant Accidents (LOCA) - Part 2: System Level Scaling for System Depressurization". Proceedings of the International Top. Meet. On Nuclear Reactor Thermal Hydraulics (NURETH-11), Avignon, France (2005)

[13] N. Zuber, W.Wulff, U.S. Rohatgi and I. Catton, “Application of fractional scalinganalysis (FSA) to loss of coolant accidents (LOCA), - Part 3. Componentlevel scaling for peak clad temperature" Proceedings of the International Top. Meet. On Nuclear Reactor Thermal Hydraulics (NURETH-11), Avignon, France (2005)

[14] A.N. Navahandi, S. Castellana and E.N. Moradkhaniav, "Scaling laws for modeling nuclear reactor systems" Nuclear Science and Engineering, 72 (1982)

[15] F. D'Auria and P. Vigni, "Proposed set of criteria in designing nuclear power plants experimental simulators" Proceedings of the International Top. Meet. On Nuclear Reactor Thermal Hydraulics (NURETH-3), Newport, USA (1985).

[16] F.D'Auria, H. Karwat and M. Mazzini, "Planning of 
counterpart tests in LWR experimental simulators." Proceedings of the ANS National Heat Transfer Conference, Houston, USA.(1988)

[17] R.C. Borges, F.D'Auria, A.C.M. Alvim, "Independent qualification of the CIAU based on the uncertainty estimate through the simulation of LOBItest BT-02", Kerntechnik 68 (1-2), 7-16.(2003)

[18] S. Yokobori, H. Nakamura, "Optimized apportion between large-scale nuclear thermal-hydraulic tests and simulation". JAE 27, pp. 461-468 (in Japanese).(2008)

[19] N.E. Todreas, M.S. Kazimi, "Nuclear Systems". Hemisphere Publishing Corp.(1990)
[20] L.S. Tong, J.Weisman, J., "Thermal Analysis of Pressurized Water Reactors". ANS La Grange Park, USA (1996).

[21] H.Ninokata, A. Aritomi, A. (Eds.),. "Sub-channel Analysis in Nuclear Reactors", AESJ,Institute of Applied Energy, ISBN 4-9900222-0-3, pp. 1-301. (1992)

[22] Y.A. Hassan, H.R. Barsamian, "New-wall modeling for complex flows usingthe large eddy simulation technique in curvilinear coordinates." International Journal of Heat and Mass Transfer 44 (21), pp. 4009-4026. (2001)

[23] S. Banerjee, M.G. Ortiz, T.K. Larson, D.L. Reeder, "Scaling in the safety of next generation reactors." Nuclear Engineering and Design vol 186, pp .111-133 (1998) 